\title{
A fuzzy-PID-concept with minimal rule set
}

\author{
Dr. F. Roß
}

TU Ilmenau, Fakultät für Informatik und Automation

D-98684 Ilmenau, Germany

Tel (+49 3677) 691417, Fax (+49 3677) 840758

Dipl.-Inf. U. Döring

R3M Softwarebüro

Unterpörlitzer Straße 8, D-98693 Ilmenau, Germany

Tel (+49 3677) 670295, Fax (+49 3677) 840758

\begin{abstract}
In this paper an new fuzzy-PID-controller-concept is described. Such fuzzy-controllers consist of only two rules. By the development of such controllers only the membership functions of the inputs and the output must be defined. Also the inference method is reduced, because an operator for the action parts of the rules is not necessary.
\end{abstract}

\section{Keywords}

fuzzy-controller, membership function, inference 


\section{Introduction}

The development of fuzzy systems, consisting of the steps fuzzification-inference-defuzzification, requires the definition of membership functions (MSF), of the inference method by choice of the operators for truth values, of the defuzzification method and last but not least of the rule set. The great number of existing Methods leads to a great number of ways to develop such fuzzy systems. Therefore special fuzzy solutions, e.g. fuzzy controllers, are developed by using of a reduced set of methods. In most cases trapezoids are used for MSF, MIN-MAX or MIN-PROD for inference and the modified center of gravity method for defuzzification. This reduces the development of fuzzy controllers to the definition of the MSF and the rule set.

In this paper we describe a new way for the design of fuzzy controllers, using only two rules. And so only the MSF must be defined.

\section{Conventional fuzzy-PID-controllers}

Like the classical PID controllers the fuzzy-PID-controllers also use control error $e(t)$, its integral and its derivative as input information. With the usual constraints like trapezoids for the input-MSF, single tones for the output-MSF and symmetry for all MSFs we can define the following rule set for a fuzzy-PID-controller:

IF $\mathrm{P}=\mathrm{NEGATIVE}$ THEN $\mathrm{U}=\mathrm{NEGATIVE}$

IF $\mathrm{P}=$ POSITIVE THEN U=POSITIVE

IF I=NEGATIVE THEN U=NEGATIVE

IF I=POSITIVE THEN U=POSITIVE

IF D=NEGATIVE THEN U=NEGATIVE

IF D=POSITIVE THEN U=POSITIVE

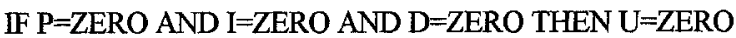

Here we use for the control error (P), its Integral (I) and its derivative (D) MSFs shown in Figure 1 and for the controller output (U) the MSF shown in Figure 2. 


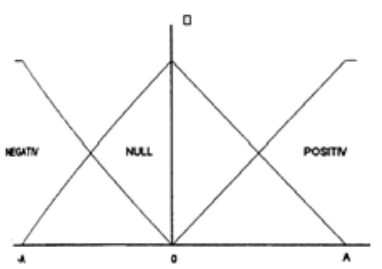

Figure 1 MSF-type for $P, I$ and D.

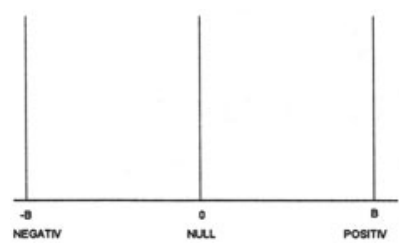

Figure 2 MSF-type for U.

This for the used MSFs minimal rule set is enlarged, if further attributes like VERY NEGATIVE or VERY POSITIVE are included. An essential disadvantage is caused by the used trapezoid form for the input MSF. In this case the transfere behavior is influenced by the break points of the MSFs (Figure 3).

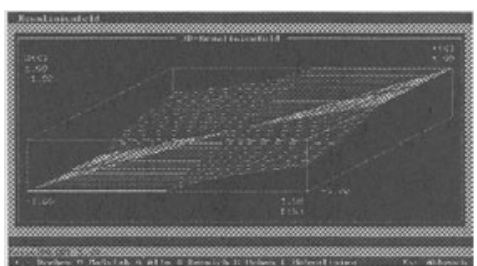

Figure 3 transfere behavior of the conventional fuzzy-PID-controller.

\section{Fuzxy-PID-controller with minimal rule set}

In the fuzzy-PID-concept shown above the MSFs contain attributes for the working point ( $\mathrm{P}, \mathrm{I}$ and D equal zero) explicitly (in the controller above this attributes are named ZERO). In contrast to this in the new fuzzy-controller we use MSFs shown in Figure 4 and Figure 5.

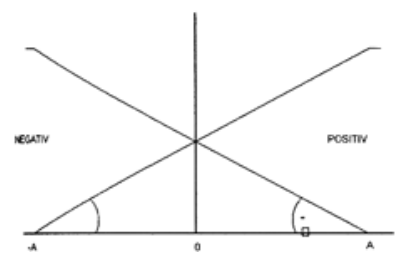

Figure 4 MSF-type for $P$, I and D.

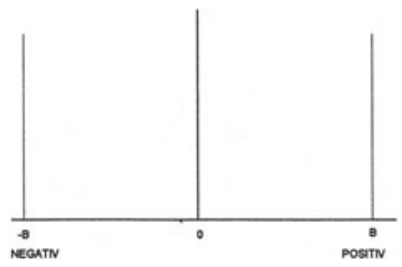

Figure 5 MSF-type for U. 
The explicit consideration of the working point is not necessary, because in this point the values of POSITIVE and NEGATIVE are equal and so they compensate each other. After the defuzzification the controller output $U$ gets value 0 . Since for the used input MSFs both attributes (POSITIVE, NEGATIVE) in the working range $[-A ; A]$ get truth values different from 0 we can define the following minimal rule set:

\section{IF $\mathrm{P}=\mathrm{NEGATIVE}$ AND I=NEGATIVE AND D=NEGATIVE THEN U=NEGATIVE IF $\mathrm{P}=$ =POSITIVE AND I=POSITIVE AND D=POSITIVE THEN U=POSITIVE}

Like classical PID-controllers the characteristic of this fuzzy-PID-controller is defined by the choise of the gains for P, I and D. Because we assume the MSFs to be symmetrical the choice of this gains is done by the choice of the angle $\alpha$ for $\mathrm{P}, \mathrm{I}$ and $\mathrm{D}$ each. This way is not possible in available fuzzy development kits. Therefore the gains can also be set by choosing the parameter $\mathrm{A}$. We recomment to use the operators ALGEBRAIC PRODUCT or ARITHMETIC SUM for the determination of the truth values of the conditional part. The offen used operator MINIMUM leads to a loss of information, because only the rule part with the minimal truth value is used. Since the contoller contains only two rules with different attributes in the action part, no combination of there truth values takes place. Therefore no additional operator is needed.

If we use trapezoids for the input MSFs, this fuzzy-PID-concept can be applied only if is ensured that the input is in the range of $[-\mathrm{A} ; \mathrm{A}]$. To overcome this disadvantage we developed a new MSFform called $X$-function. The equation is:

$$
\begin{aligned}
& \mu_{\text {POSIITV }}=1 /(2-X \cdot S) \text { for } X \leq 0 \\
& \mu_{\text {POSITV }}=1-1 /(2-X \cdot S) \text { for } X>0 \\
& \mu_{\text {NEGATIV }}=1-\mu_{\text {PosirTV }}
\end{aligned}
$$

where $\mathrm{S}$ is the rise in the working point and $\mathrm{X}$ stands for control error, its integral or its derivativ respectivly (Figure 6).This MSF reaches the value 0 only for infinite values of X. So it is ensured, that really all conditional parts of the both rules ever yield a truth value greater zero an both rules are firing. If the X-function is used, further MSF-attributes like VERY NEGATIVE or VERY 
POSITIVE do not increase the rule set. The following rule set can be defined for the MSFs shown in Figure 7 .

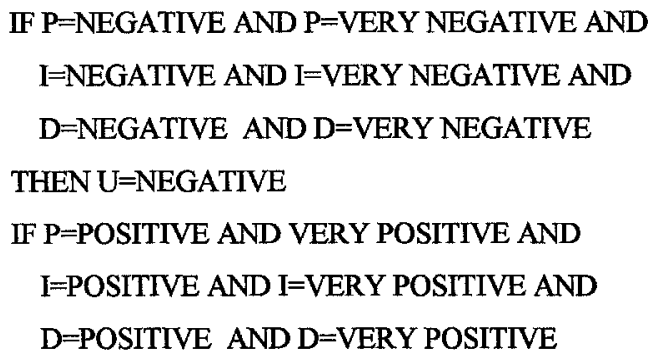

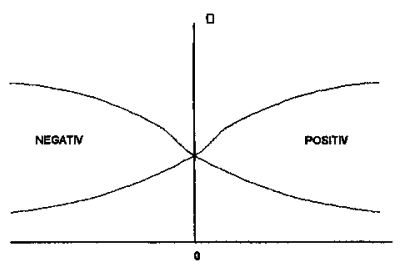

Figure $6 \mathrm{X}$-function.

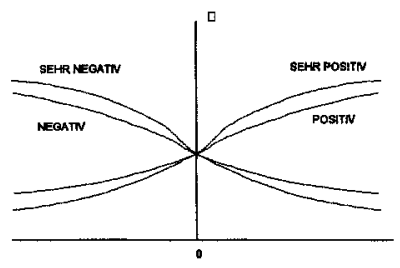

Figure 7 enhanced X-function-MSF.

Systems with one output and multiple inputs (MISO) also do not increase the rule set. So an inverse pendulum can be stabilized with the following rules:

IF P1=NEGATIVE AND D1= NEGATIVE AND P2=NEGATIVE AND D2=NEGATIVE THEN U=NEGATIVE

IF P1=POSITIVE AND D1= POSITIVE AND P2=POSITIVE AND D2=POSITIVE THEN $\mathrm{U}=$ POSITIVE

Here is:P1 position of the car

D1 velocity of the car

P2 angle of the pendulum

D2 angular velocity of the pendulum 


\section{Conclusions}

In this paper we described a new fuzzy-PID-controller with the following advantages over known fuzzy-PID-concepts:

1. The rule set is minimal and constant.

2. The behavior contains no break points (Figures 8 and 9).

3. More attributes do not increase the number of rules.

4. More system outputs do not increase the number of rules.

5. Only one operator for the determination of truth values is necessary.

6. The controller can be optimized well by known methods.
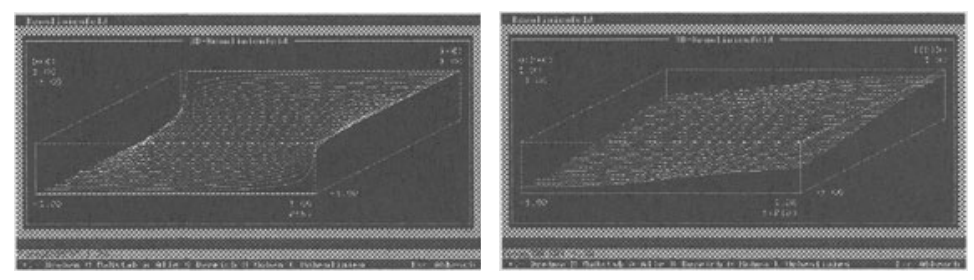

Figures 8 and 9 Behavior of the new fuzzy-PID-controller

The fuzzy-PID-concept described in this paper was used e.g. with an real invers pendulum, by the control of robots and by the on-line adaption of classical PID-controllers. Here we got very good results. The definition, the test and the optimization of such fuzzy-PID-controllers are possible with the fuzzy development tools FuzzyEXPERT and FuzzyEXPERT for Windows. 